Scientists appreciated how non-scientific participants were constructively interested and able to get to grips with key aspects of a complex subject. The latter, meanwhile, usually starting from zero, gained knowledge about what scientists are doing and about their motivation, and a greater awareness of the potential impacts - both real and hyped.

But what's the point of such engagement? One positive example inspired many subsequent activities: the 2004 report on nanoscience and nanotechnology by the British Royal Society and the Royal Academy of Engineering. This was productive not only in its content but also in the way the various processes of engagement enhanced its public credibility and helped ensure that the questions it addressed were of appropriate scope.

A more recent example was a series of 'Nanodialogues', workshops conducted by the UK think-tank Demos unveiled last week (see www. demos.co.uk/publications/nanodialogues). One workshop, involving Unilever, showed how issues of corporate social responsibility arise not only in manufacturing processes and products but also in corporate R\&D. Another, conducted in a village near Harare in Zimbabwe, demonstrated how remote from reality are some claims made for nanotechnology's potential impact on water purification in the developing world.

A nanodialogue in Swindon involved engagement between 14 local citizens and scientists funded by two UK research councils based there. Here was an example of true 'upstream engagement', the idea - often suspiciously received by scientists - that both the public and scientists have something to gain from discussing future research prospects as an input to research funding. Most encouraging for researchers was the strong support by public participants for fundamental science.
A taste of true upstream thinking by nanoscientists can be found in blogs at http://ideasfactory.wordpress.com. These feature futuristic nanotechnology concepts, including software-controlled assembly of a variety of building-blocks (small molecules to nanoparticles) linked by covalent bonds, and the development of a flexible machine, computer language and compiler as an assembler of molecules and materials under atomically precise control.

These are potentially powerful enabling technologies. To take a view on their risks or values, either as a scientist or as a citizen, depends on imagined contexts of application. The benefit of the public engaging with scientists years
"Most encouraging for researchers was the strong support by public participants for fundamental science." or even decades ahead of the arrival of such technologies lies in the broadening of the bases of knowledge, mutual trust and - most importantly - critical appraisal. One challenge now is how to allow a much larger proportion of the public to share in those benefits.

Few governments have put solid investment in the one type of research most consistently and urgently demanded by these groups - on the health and environmental risks of technologies already embedded in hundreds of products on store shelves. Commendably, a new Australian initiative in nanotechnology research includes such investment.

Regrettably, the governments of two countries that have taken strong leads in nanotechnology - the United States and Britain have failed to respond. These governments and others not only need to act on this outcome of public engagement but must also integrate such processes into their departments' and agencies' activities.

\title{
Discriminating on genes
}

\section{The United States is belatedly establishing necessary protections in law. Others, take note.}

n a rare departure, President George W. Bush, the House of Representatives and most of the US Senate have found a landmark piece of legislation on which they can agree. The Genetic Information Nondiscrimination Act of 2007 was passed overwhelmingly by the House late in April. The bill would bar insurers from using the results from genetic tests to deny coverage to new applicants, or from hiking the price of premiums for existing customers. It would also make it illegal for employers to use genetic information in hiring, firing or promotion decisions. (Shamefully, however, military personnel are excluded from the act's protections.) Such protections are sorely needed in many countries, but certainly in the United States, where employers and private insurers pay a significant proportion of health costs and have every reason to try to minimize the health risks of those they hire or insure.

Despite the endorsement of the White House and strong historical support for such a measure in the Senate, the bill is still awaiting a Senate vote. It has been delayed by a crammed legislative calendar and by behind-the-scenes wrangling of lawmakers over issues ranging from the measure's definition of a genetic test to whether the bill as written would allow violators to be sued twice for the same offence.

These negotiations should be concluded soon. There have seldom been so many good reasons to see a bill speedily enacted. Public concerns about the potential abuse of genetic information have risen steadily in the past decade. Leading voices, from the White House to top geneticists such as Francis Collins, argue that this threatens both the beneficial use of more than 1,100 clinically available genetic tests and the ability to conduct further research. Genetic studies rely, after all, on the good will of thousands of subjects who agree to have their DNA scrutinized. Without solid legal protection in place, people will remain justifiably wary of being tested, whether for research or for their personal health. The wealth of information now pouring out - for instance, in a raft of genome-wide association studies that are targeting suspect genes in complex diseases such as diabetes - will not be fully exploited, and the benefits of personalized medicine will be, at best, only partially realized.

Given the nature of its private-insurance system, it is apt that the United States should be leading the way with the current legislation. The Charter of Fundamental Rights of the European Union includes "genetic features" in its non-discrimination protections, and individual countries are charged with making their domestic laws compatible with it. Yet many countries - France and Austria are notable exceptions - have so far failed to enact an explicitly protective genetic information law. In this, they could take a leaf from the US book - provided that the book finally gets written. 